Research Article

\title{
Experimental and Mathematical Modeling of Monotonic Behavior of Calcareous Sand
}

\author{
Haotian Zhang, ${ }^{1}$ Zongmu Luo $\mathbb{D}^{1},{ }^{1}$ Yanyu Qiu, ${ }^{1}$ Huachao Liu $\mathbb{D}^{1},{ }^{1}$ Juan Gu, ${ }^{1}$ and Jian Tang ${ }^{2}$ \\ ${ }^{1}$ State Key Laboratory of Disaster Prevention \& Mitigation of Explosion \& Impact, Army Engineering University of PLA, \\ Nanjing 210007, China \\ ${ }^{2} 31619$ PLA Troops, Zhenjiang 212421, China
}

Correspondence should be addressed to Zongmu Luo; langdon0114@163.com and Huachao Liu; 273750748@qq.com

Received 12 May 2020; Revised 22 June 2020; Accepted 13 July 2020; Published 31 July 2020

Academic Editor: Li Chen

Copyright (c) 2020 Haotian Zhang et al. This is an open access article distributed under the Creative Commons Attribution License, which permits unrestricted use, distribution, and reproduction in any medium, provided the original work is properly cited.

\begin{abstract}
The prominent performance of wave elimination and energy absorption makes calcareous sand important and useful in infrastructure construction and protection engineering. Due to the high compressibility induced by remarkable intragranular void and irregular shape, calcareous sand presents different mechanical behaviors from common terrestrial sands. Considerable efforts have been made to explore the static and dynamic mechanical properties of calcareous sand. In this paper, a series of monotonous experiments have been performed on calcareous sand utilizing the electrohydraulic servo-controlled test apparatus designed by the Global Digital Systems Ltd (GDS). The effects of confining pressure and relative density on the mechanical properties of dry, drained, and undrained saturated sand were studied, and the underlying micromechanism of deformation and failure was discussed. It can be found that the residual stress of dry calcareous sand is independent of the relative density, while the peak stress and residual stress of drainage saturated sand have a positive correlation with the relative density. The increase of confining pressure makes the strain softening more remarkable and heightens the peak stress and residual stress. The stress-strain curve of calcareous sand can be divided into two portions: prepeak portion and postpeak softening portion. For the dry sand and drainage saturated sand, the softened part can be partitioned into three phases, i.e., accelerated phase, steady phase, and degradation phase, while the undrained saturated sand tends to hyperbolic softening. A mathematical model composed of a hyperbolic function and an inverted S-shaped function was formulated to describe the multiphase characteristic, in which the setting of parameter $p$ expands its applicability. The experimental result validated the model, showing that the model can better describe the monotonic stress-strain relationship of calcareous sand. Besides, the physical meanings of model parameters were discussed.
\end{abstract}

\section{Introduction}

In the past few decades, sea-sand as a building material has been getting more attention. Many countries, such as the UK [1] and Japan [2, 3], regard sea-sand as an alternative material for river sand. The geological origin of sea-sand is similar to that of river sand $[4,5]$, but the surface texture affecting the interlocking effect is different [6-8]. Besides, there is more salt and debris of marine creature (like sea shell) in sea-sand [9]. The debris of marine creature is even deemed to the key difference between river sand and seasand [10]. Therefore, the mechanical performance of seasand is quite different from that of river sand.
Calcareous sand is a special kind of sea-sand, mainly distributed in the marine area between $\mathrm{N} 30^{\circ}$ and $\mathrm{S} 30^{\circ}$. It has been widely used in the construction on islands and reefs. On the one hand, calcareous sand is the main material for marine reclamation land and protective engineering [11-18]. On the other hand, calcareous sand is also an important raw material for fine concrete aggregate $[19,20]$. It should be noted that calcareous sand has different mechanical properties from terrestrial sands such as silica sand. The main reason is that the skeleton of calcareous sand is formed by the fragments of marine life (such as corals, shells, and mollusks), and its particles have significant internal void spaces and various irregular shapes $[21,22]$. The difference 
in mechanical properties leads to the foundation stability, strength, and durability of calcareous sand concrete buildings different from those of general concrete buildings. Furthermore, as a typical loose granular material, calcareous sand is widely used in protective engineering, which often involves the dynamic loading scenarios. Based on the impact test by the split Hopkinson pressure bar (SHPB) device, the law of stress wave attenuation in calcareous sand has been revealed. By measuring variables such as stress wave propagation speed and peak stress, it is found that the wave attenuation effect and the energy absorption properties of calcareous sand was better than those of terrestrial sand [14-17]. Hence, calcareous sand is of great importance in infrastructure construction and protection engineering. The mechanical properties of calcareous sand under monotonic loading are the basis for investigating its dynamic mechanical response, which can provide a beneficial reference for impact load experiment, explosion effect research, and protection engineering design. Meanwhile, it is significant to establish an effective and simple model that can accurately describe the mechanical characteristics of calcareous-sand under monotonic loading.

There are considerable constitutive models for sand at monotonic loadings in the available literatures. These models have been proposed under the premise of simplification and assumption with limitation of application scope in essence. Therefore, the advantages and disadvantages of the models should be clarified when applying these theoretical models. Among them, the hyperbolic elastic model of Duncan and Chang [23] is widely used for granular materials due to its simplicity and convenience. Nevertheless, it cannot reflect the strain-softening behavior. It appears that the models are more and more satisfactory in describing the essential behavior features of sand, but the theoretical framework and the application still need to be further investigated.

(i) Nonlinear elastic model [23-25]: this kind of model can be consistent with the experimental results as long as the model parameters are enough. The nonlinear nature of the soil can be reflected, and the model parameters with distinct physical significance can be determined by conventional tests. The models have been widely used in practical engineering and are generally suitable for strain hardening materials such as footings on sand and clay. However, they cannot be applied to geotechnical materials with strain softening characteristics due to relatively large deviation of calculation results. In addition, the models cannot reflect the influence of intermediate principal stress and the dilatancy of soil, so their scope of application are limited.

(ii) Elastic-plastic model [26-31]: this kind of model has a more rigorous theory framework, which can predict the soil properties under various load conditions, thus have a wider application field. The results of research on cohesionless soils such as river sand show that the model can be used to predict the soil performance of drained and undrained conditions from typical dense sand to typical loose sand. The postpeak behaviors of strain hardening and strain softening are also modeled correctly. But, there are some difficulties in determining up to fourteen model parameters. In addition, these models are sometimes not practical in practice because the theoretical description is too complex.

(iii) Hypoplastic model [32-35]: in these models, the relationship between stress rate and strain rate is directly constructed at the framework of thermodynamic theory. The constitutive relations established can be expressed by simple mathematical expression, and the influence of stress path can be considered. Since the concepts such as double yield surface and anisotropic hardening criterion are introduced, the practical ability of the models is strengthened, and the complex constitutive characteristics of soil are described. Although the theoretical complexity is decreased, the model parameters are not easy to be obtained.

(iv) Critical state model [36-40]: in this type of model, a state parameter is achieved based on the critical state theory. The introduction of the state parameter enables these constitutive models to take into account the mechanical behavior related to the change of material state during loading. Therefore, the deficiency of treating loose and dense sandy soil as different media has been overcome. Some of these models even fit for both sand and clay. However, there are more model parameters such as confining pressure and load path, and the parameter determination is also complex.

In fact, it is very difficult to completely and accurately describe the complex deformation characteristics of the sand under any conditions. The various kinds of models aforementioned demonstrate that there is a contradiction between the accurate description and application complexity. Therefore, a balance between accuracy and complexity should be reached in a model based on the user demands. In this paper, a series of monotonous experiments have been performed on calcareous sand, and the corresponding stress-strain curves are obtained and analyzed. A mathematical model describing the complete stress-strain curves is proposed, and its feasibility is verified by the test results. Moreover, the physical meanings of model parameters are discussed.

\section{Monotonic Behavior of Calcareous Sand}

2.1. Sand Samples Tested. The calcareous sand used in this study was obtained from the South China Sea between $\mathrm{N} 4^{\circ}$ and $\mathrm{N} 16^{\circ}$. It was mainly medium-fine sand and consists of coral fragments. The energy-dispersive X-ray spectroscopy was used for elemental analysis of sand sample, showing that the mineral composition is composed of as high as $97 \%$ calcium carbonate with specific gravities of $2.7 \sim 2.85$ and is mainly composed of $33 \% \sim 47 \%$ aragonite and $53 \% \sim 67 \%$ high magnesian calcite [41]. The surface texture was observed by scanning electron microscopy (SEM), as shown in Figure 1. The SEM images indicate that there are many pores distributed around the particle surface. The porous characteristic leads to more interlocking parts between angular grains in calcareous sand than those in ordinary terrestrial sands. 


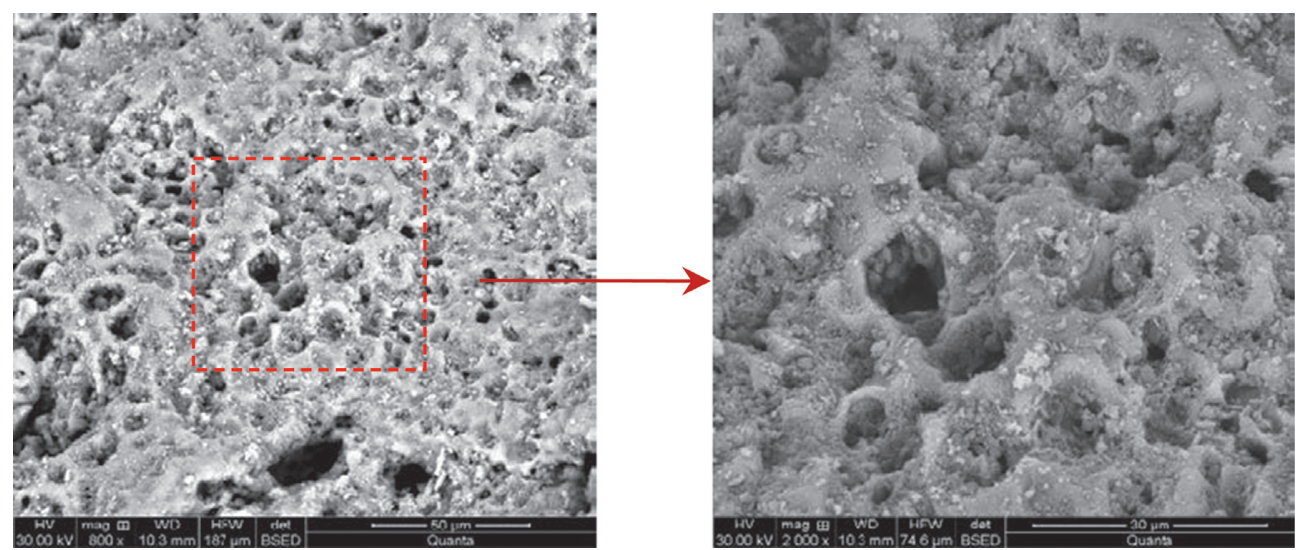

FIgURE 1: SEM image of calcareous sand.

In this study, the grains coarser than $2 \mathrm{~mm}$ were removed and the corresponding grain size distribution curve is shown in Figure 2. Considering the effect of relative density, the specific gravity and the maximum and minimum dry densities were measured according to ASTM standard D5550 and D5253, respectively $[42,43]$. The results are summarized in Table 1.

2.2. Test Equipment and Methods. The electrohydraulic servocontrolled dynamic triaxial test system (DYNTTS) developed by GDS has been used in this study, as shown in Figure 3. It integrates the triaxial cell and the axial pressure driver. Axial load and axial deformation are controlled by the bottom of the triaxial cell. The standard pressure/volume controllers are used for confining pressure and back pressure, respectively. By means of high accuracy transducers and a powerful data collector, the axial force, vertical displacement, and pore pressure are measured and recorded. The built-in software of the computer control system is utilized to precisely control the test conditions and receive data in real time.

The samples were all cylindrical with a diameter of $50 \mathrm{~mm}$ and a height of $100 \mathrm{~mm}$. According to the relative density designed by the test scheme, the samples were arranged by the layered packing method. For saturated calcareous sand, the confining pressure and back pressure were increased every 20 minutes while maintaining an effective confining pressure of $5 \mathrm{kPa}$. Each increase was $100 \mathrm{kPa}$ until the pore pressure parameter $B$ exceeded 0.98 , where $B$ is the ratio of the increment of internal pore water pressure to the increment of back pressure. In the experiment, the sand samples were fully saturated after the back pressure reached $500 \mathrm{kPa}$. After that, the specimens were isotropic consolidated under certain values of effective confining pressure. For dry sand, the confining pressure directly increased to the preset value and remained constant. The consolidation was completed when the deformation of the sand sample stabilized. Finally, monotonic triaxial tests were performed on calcareous dry sand and calcareous saturated sand under undrained/drainage condition. All the tests were controlled by axial displacement. For dry sand and saturated sand under undrained condition, the loading rate was $0.5 \mathrm{~mm} / \mathrm{min}$. For saturated sand under drainage condition, the loading rate was $0.01 \mathrm{~mm} / \mathrm{min}$.
For the calcareous sand with the relative density of $30 \%$, $45 \%$, and $60 \%$, respectively, the monotonic triaxial tests were carried out under the initial effective confining pressure of $100 \mathrm{kPa}, 200 \mathrm{kPa}$, and $300 \mathrm{kPa}$, respectively. The specific test scheme is shown in Table 2.

2.3. Typical Stress-Strain Curves. Figure 4 shows the test result of dry calcareous sand with the relative densities of $D_{r}=30 \%, 45 \%$, and $60 \%$. The confining pressures were all $200 \mathrm{kPa}$. From Figure 4, it can be found that the loose calcareous sand presents a similar complete stress-strain curve with the denser calcareous sand. The stress-strain curves can be divided into two portions: the prepeak portion (OA section) and the postpeak portion (AD section). After the axial stress reaches the peak point, calcareous sand presents a state of strain-softening, which is a process of progressive failure. The negative tangent slope of stress-strain curve can be used to characterize the softening rate. The larger the tangent slop is, the smaller the softening rate is. Based on the change of softening rate, the postpeak strain-softening portion can be further divided into three phases:

(i) Accelerated phase (section $A B$ ): in this phase, the tangent slope gradually decreases from zero, which means that the corresponding softening rate continuously increases. Therefore, the first phase can be called accelerated phase. The starting point $A$ (peak stress) is related to the relative density.

(ii) Steady phase (section $B C$ ): when the tangent slop decreases to the minimum, the stress-strain curve develops into the secondary phase. In this phase, the softening rate is the largest and maintained constant. Thus, the secondary phase $B C$ can be called steady phase.

(iii) Degradation phase (section $C D$ ): in this phase, the tangent slope begins to increase until to zero. It means that the corresponding softening rate continuously decreases. Based on this, section $C D$ is the degradation phase. The ending point $D$ (residual stress) is independent of relative density. 


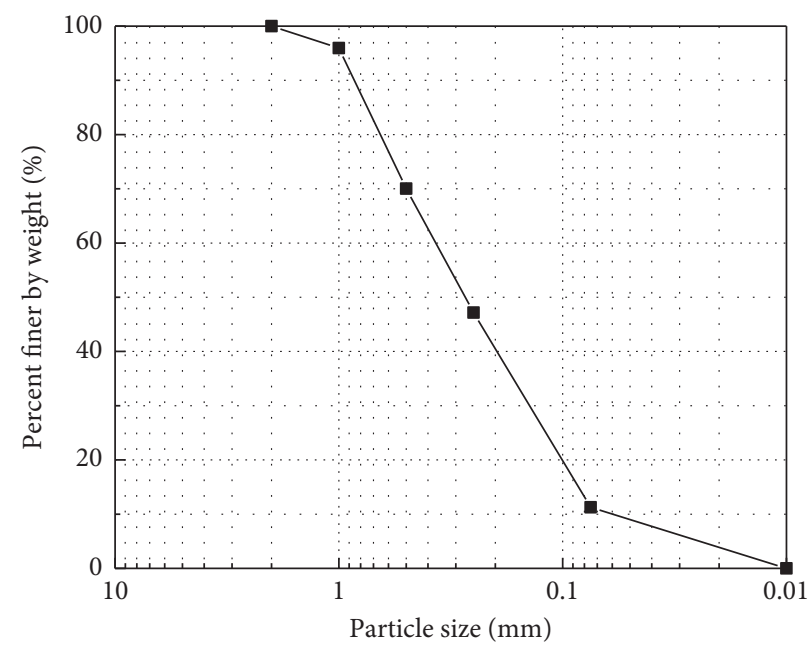

FiguRE 2: Grain size distribution curve of sand samples tested.

Table 1: Physical properties of test calcareous sand.

\begin{tabular}{lccccc}
\hline Property & $G_{s}$ & $D_{10}(\mathrm{~mm})$ & $C u /\left(D_{60} / D_{10}\right)$ & $\rho_{d \min }\left(\mathrm{g} \cdot \mathrm{cm}^{-3}\right)$ & $\rho_{d \max }\left(\mathrm{g} \cdot \mathrm{cm}^{-3}\right)$ \\
\hline Calcareous sand & 2.807 & 0.055 & 7.3 & 1.14 & 1.48 \\
\hline
\end{tabular}

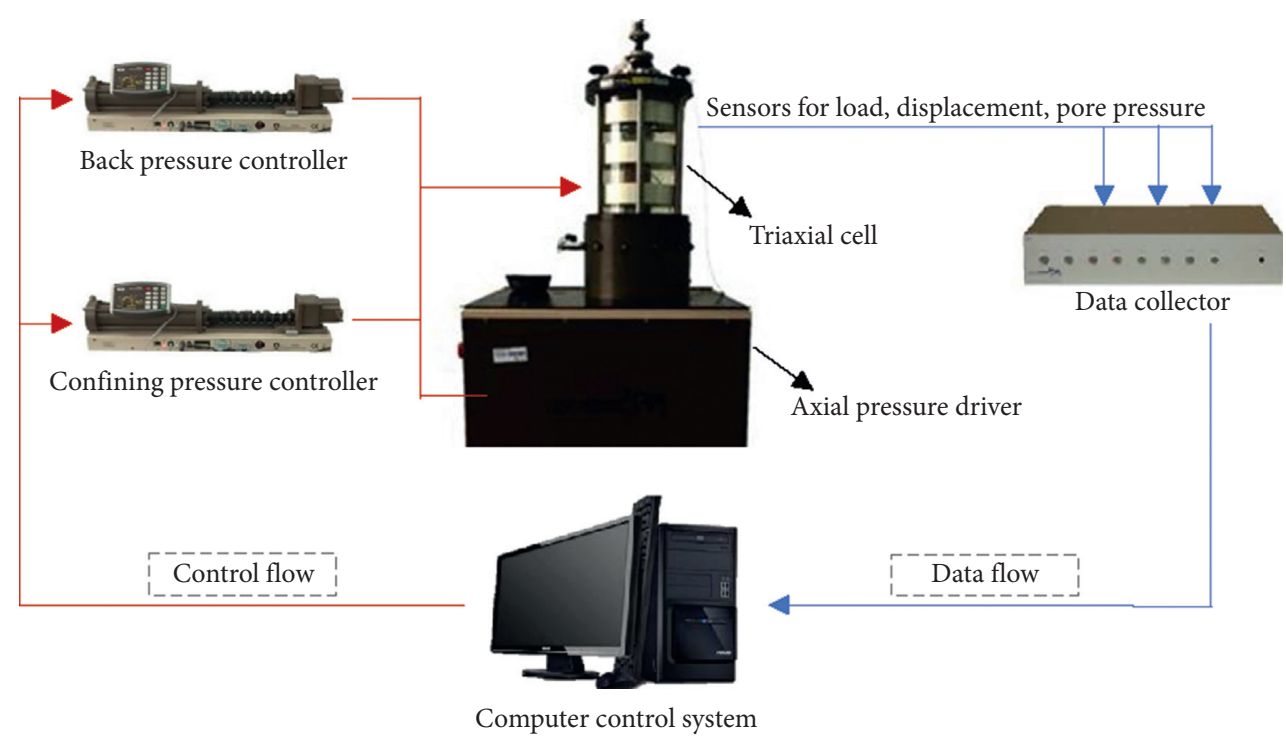

Figure 3: GDS dynamic triaxial test system.

The stress-strain curves of dry calcareous sand with a relative density of $30 \%$ under different confining pressure are shown in Figure 5. It is found that both of the stressstrain curves at low and high confining pressure can be divided into two portions: prepeak portion and postpeak portion of three phases. Especially, the larger the confining pressure is, the more obvious the strain-softening of three phases is. The starting and terminal points of postpeak portion are both related to the confining pressure. Specifically, the larger confining pressure corresponds to the higher starting and terminal points.

The stress-strain curves of saturated calcareous sand at drained triaxial compression are shown in Figure 6 . The test results indicate that the stress-strain curves of saturated calcareous sand at drained compression can also be divided into prepeak portion and postpeak portion of three phases. The starting and terminal points of strain-softening are both related to the relative density and the initial effective confining pressure. The accelerated phase occupies a higher proportion in the total deformation process, exceeding the steady phase in this test condition, while the deformation during the accelerated phase is less than that during the steady phase for dry sand.

Saturated Nevada sand and saturated Toyoura sand (data from [44]) have been compared, of which some physical properties are presented in Table 3. Compared with the two sands, calcareous sand presents a larger strain-softening, as 
TABLE 2: Scheme of the monotonic triaxial tests.

\begin{tabular}{lccc}
\hline $\begin{array}{l}\text { Test } \\
\text { number }\end{array}$ & Condition & $\begin{array}{c}\text { Relative density } \\
(\%)\end{array}$ & $\begin{array}{c}\text { Confining pressure } \\
(\mathrm{kPa})\end{array}$ \\
\hline$D-01$ & - & 30 & 100 \\
$D-02$ & - & 30 & 200 \\
$D-03$ & - & 30 & 300 \\
$D-04$ & - & 45 & 200 \\
$D-05$ & - & 60 & 200 \\
$S-01$ & Undrained & 30 & 100 \\
$S-02$ & Undrained & 30 & 200 \\
$S-03$ & Undrained & 30 & 300 \\
$S-04$ & Undrained & 45 & 200 \\
$S-05$ & Undrained & 60 & 200 \\
$S-06$ & Drainage & 30 & 100 \\
$S-07$ & Drainage & 30 & 200 \\
$S-08$ & Drainage & 30 & 300 \\
$S-09$ & Drainage & 45 & 200 \\
$S-10$ & Drainage & 60 & 200 \\
\hline
\end{tabular}

In the column of the test number, $D$ represents dry sand and $S$ represents saturated sand. For each case, the experiment was repeated two times. The average value was taken as the final result under the premise of good repeatability.

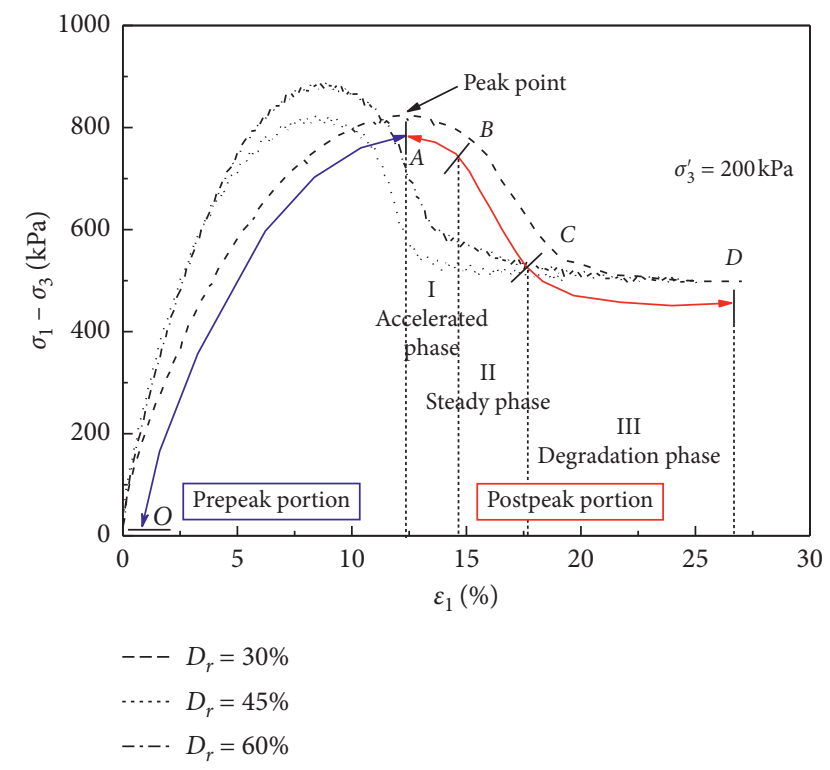

FIGURE 4: Stress-strain curves of dry calcareous sand with different relative densities.

shown in Figure 7. The postpeak portion of calcareous sand is three-phased, while that of Nevada sand is two-phased. For Toyoura sand, the strain-softening portion is even approximately linear. The larger strain-softening is due to the higher compressibility of calcareous sand. Besides, the multiphase characteristic is closely related to the contact between particles. Considering the porous property, the more interlocking parts in calcareous sand may be the main cause of the three-phase softening.

The stress-strain curve of saturated calcareous sand at undrained triaxial compression is different from that of dry calcareous sand, but it is similar to that of other sands, as shown in Figure 8. When the initial effective confining

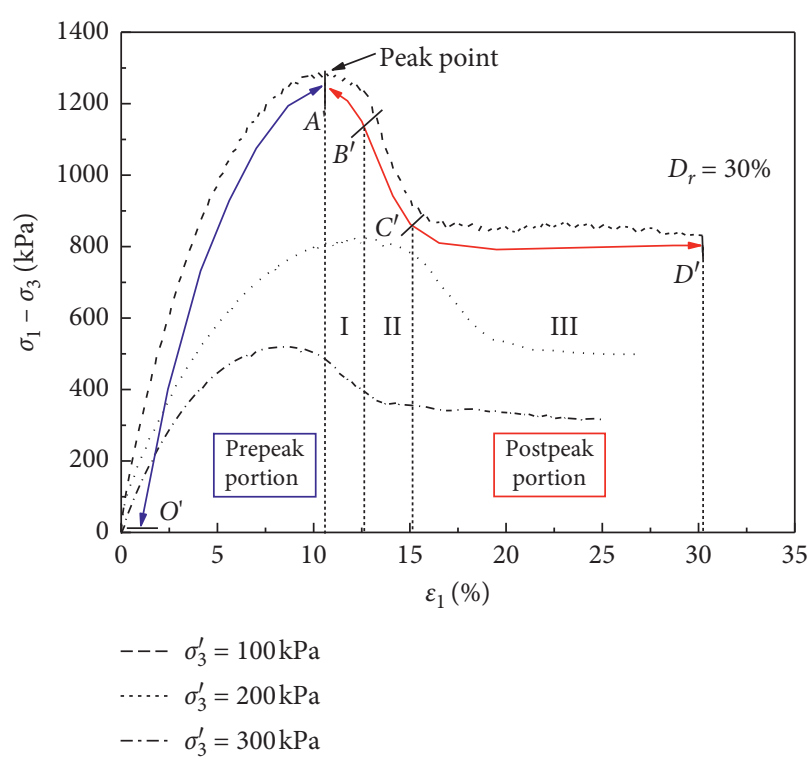

Figure 5: Stress-strain curves of dry calcareous sand at different confining pressures.

pressure is relatively low, the stress-strain curve of calcareous sand presents hyperbolic relationship without strainsoftening phase under undrained compression. The stressstrain curve at a high initial effective confining pressure is composed of two portions: prepeak portion and postpeak portion. However, the postpeak portion is not three-phased but behaves as a hyperbolic softening like Toyoura sand.

2.4. Micromechanism of Deformation and Failure. The deformation of calcareous sand is mainly a process of coupled development between particle slip and breakage [45], as shown in Figure 9. During the slip process, particles mainly resist deformation by friction, while the crushing process is accompanied by interlocking effect. When the stress reaches the strength of the particles, the crushing occurs and causes deformation. At the initial stage of loading, the contact between particles is not close, so the slippage is relatively easy. At this time, the pressure bearing mainly depends on the interlocking between particles. With the increase of axial pressure, the particles are gradually broken and the occlusal structure is increased. However, the breakage and abrasion of the sharp corners reduce the roughness of the particle surface, which weakens the interlocking effect. Meanwhile, the overall contact between particles becomes tighter as the test progresses, resulting in a more prominent friction effect. Moreover, particle crushing releases internal pores, increases the friction area, and further enhances the friction effect. In general, under the cooperation of interlocking and friction, monotonic experiments of calcareous sand show the phenomenon of strain hardening and multiphase strain softening, which is more complicated than the samples with better roundness and less breakage, such as the Nevada sand and the Toyoura sand. Under undrained conditions, pore water changes the relative motion of particles and weakens the softening degree of calcareous sand. 


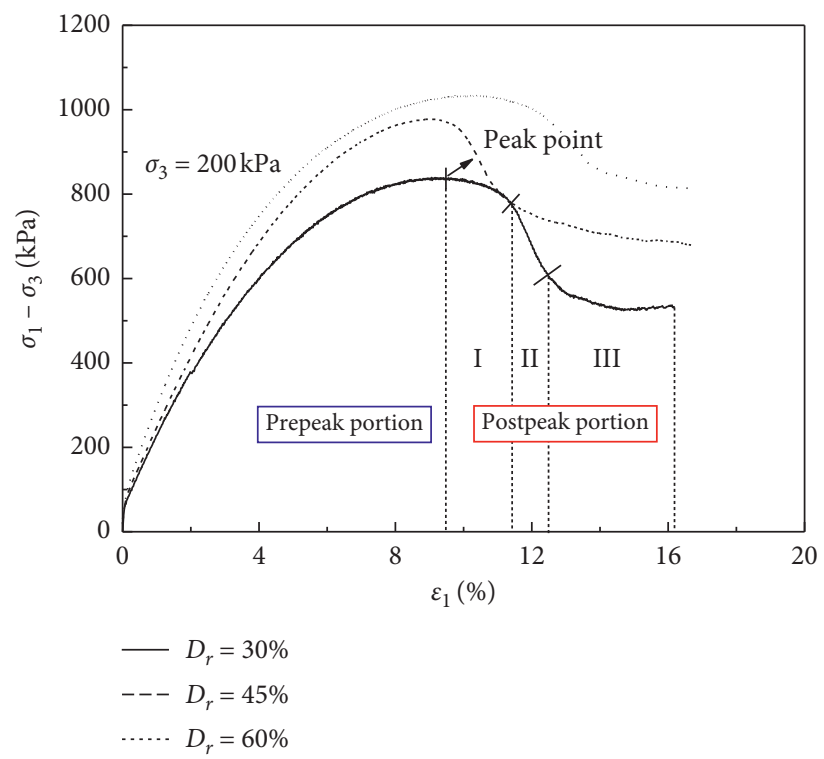

(a)

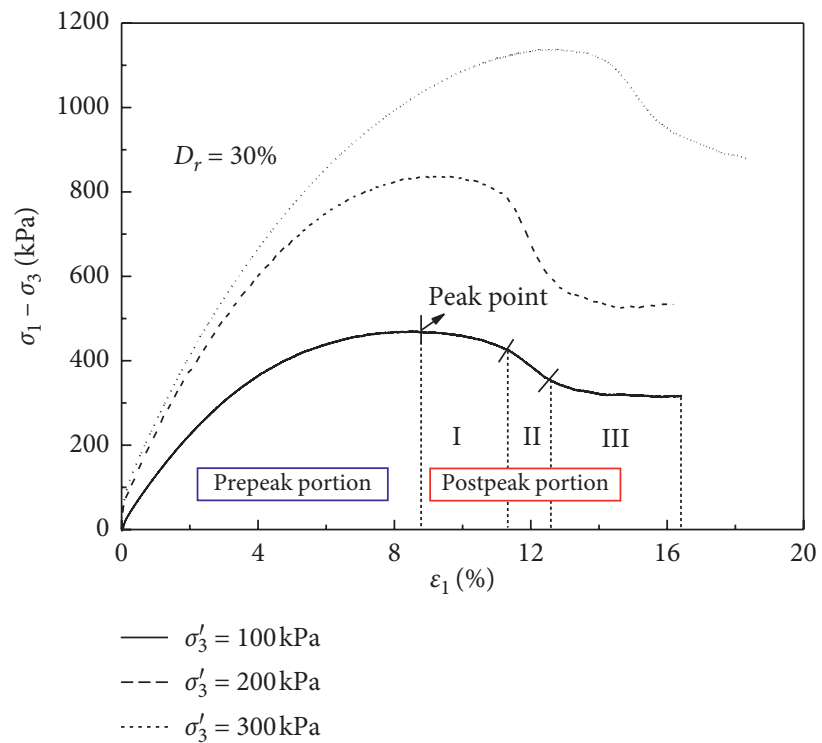

(b)

Figure 6: Stress-strain curve of saturated calcareous sand at drained compression. Tests on specimens (a) with different relative densities and (b) at different confining pressures.

TABle 3: Physical properties of Nevada sand and Toyoura sand.

\begin{tabular}{lccccc}
\hline Property & $G_{s}$ & $D_{50} / \mathrm{mm}$ & $C u /\left(D_{60} / D_{10}\right)$ & $\rho_{d \min }\left(\mathrm{g} \cdot \mathrm{cm}^{-3}\right)$ & 1.387 \\
\hline Nevada sand & 2.67 & 0.15 & - & $\rho_{d \max }\left(\mathrm{g} \cdot \mathrm{cm}^{-3}\right)$ \\
Toyoura sand & 2.65 & 0.17 & 1.7 & 1.340 & 1.733 \\
\hline
\end{tabular}

From the perspective of force chain evolution, the mechanism of deformation and failure can be further explained. When pressure is applied to calcareous sand, the relative positions of the particles are adjusted. The particles aggregate to form the initial load-bearing structure, and a series of force chains are formed in the direction of the principal stress. The form of the force chain network is determined by the contact and interaction between particles, which affects the deformation. Through microscopic observation [46], it can be found that there are mainly three ways of contact between particles, namely, point-like contact, extended contact, and contact L-S (a large grain in contact with many small grains). The schematic diagram is shown in Figure 10. Point-like contacted particles are prone 


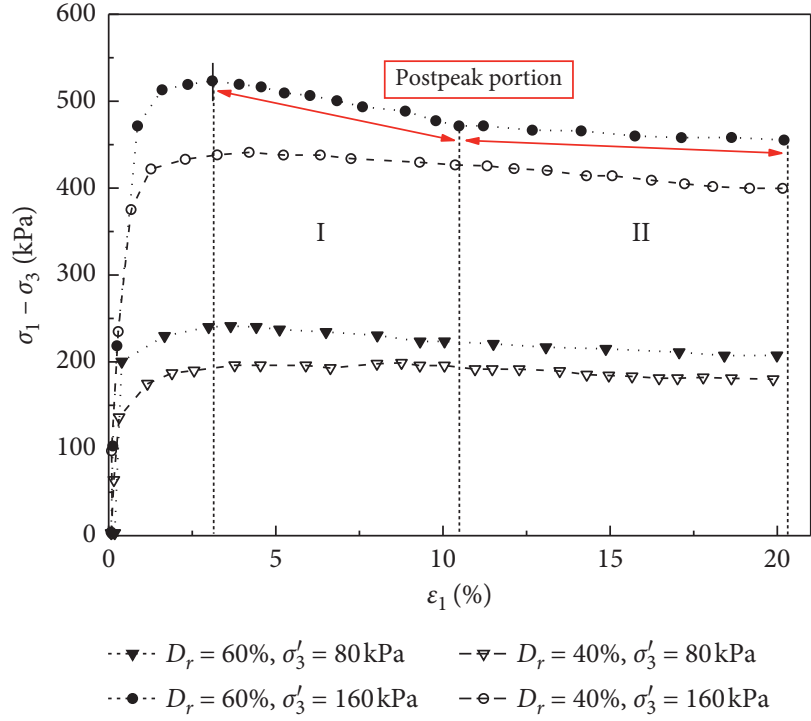

(a)

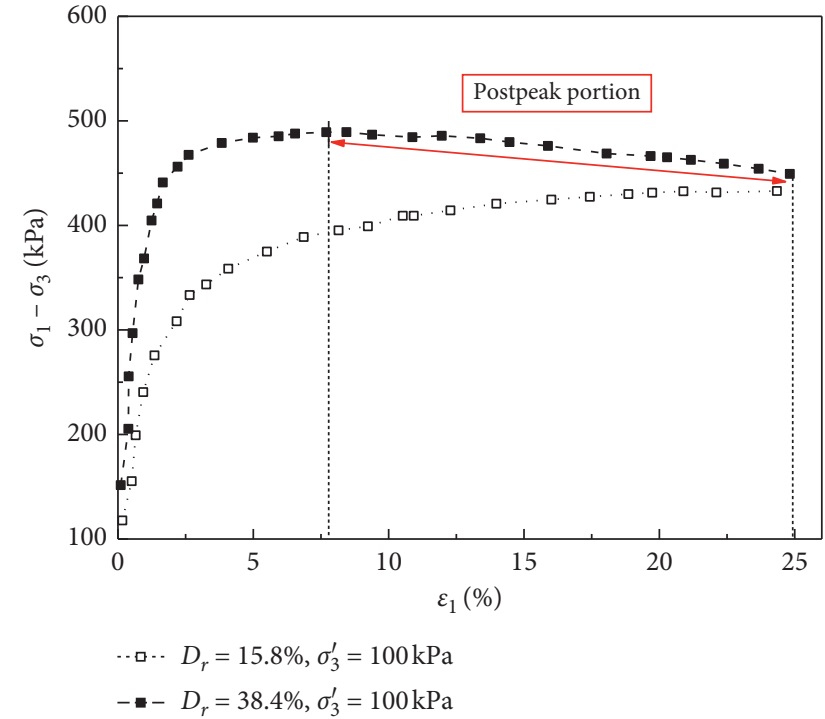

(b)

Figure 7: Stress-strain curves of sand at drained compression (data from [44]). (a) Nevada sand. (b) Toyoura sand.

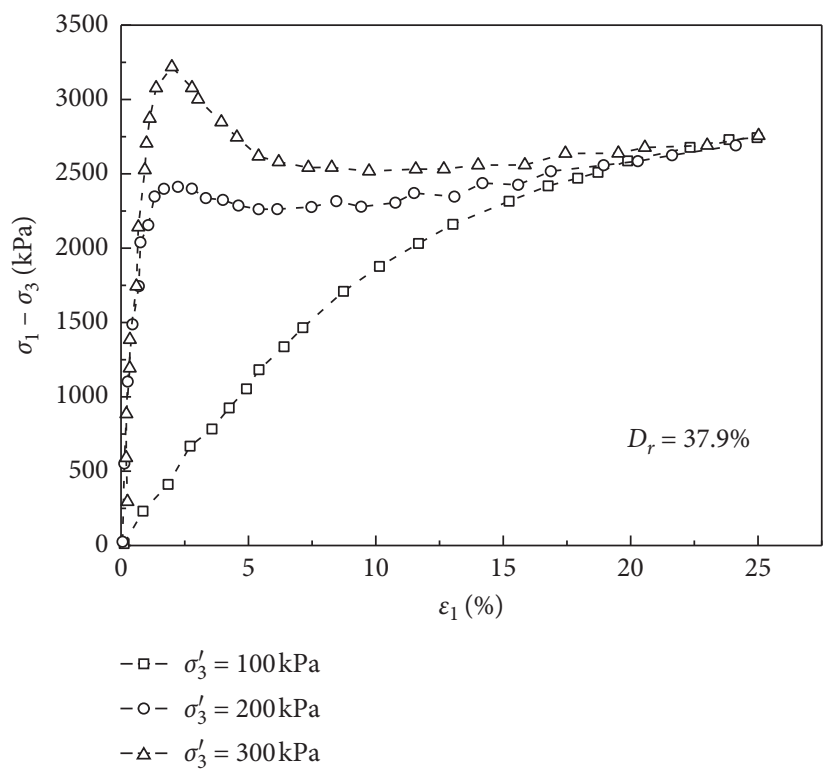

(a)

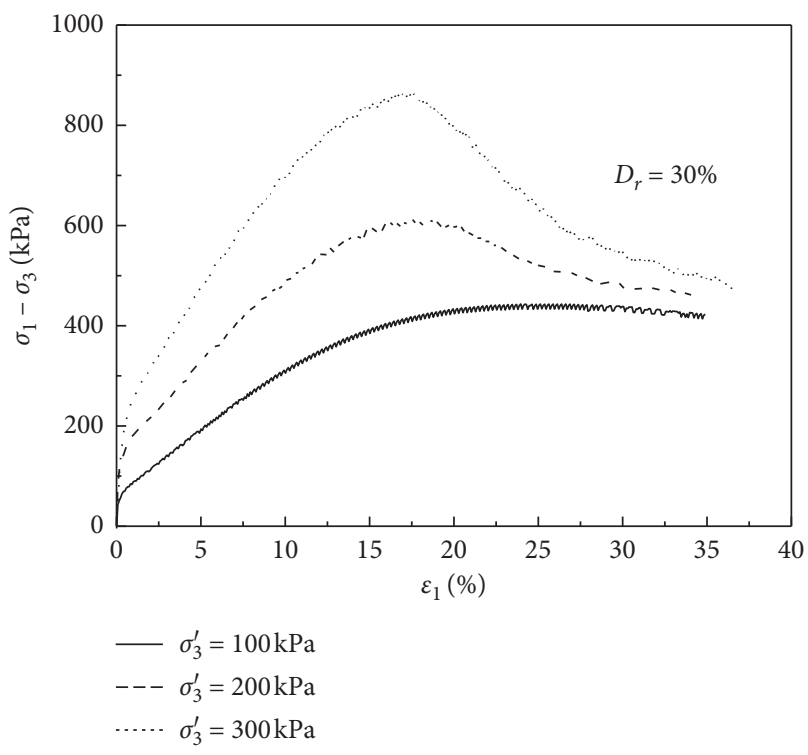

(b)

FIGURE 8: Stress-strain curves of sand at undrained compression. (a) Calcareous sand. (b) Toyoura sand (data from [44]).

to wear and damage under the effect of stress concentration, causing preliminary strain softening; meanwhile, the sharp corners with higher strength cause the particles in contact with them to split, and the slippage of the new fine particles accelerate the strain softening; particle fragmentation promotes the development from point-like contacts to extended contact. At this time, the contact area between the particles is larger, and the particles are hard to be destroyed. In addition, the breakage of particles makes the grading better, then contact L-S is easily formed when large particles are surrounded by small particles. Small particles support large particles well and produce a confining pressure-like effect, reducing the degree of particle fragmentation and suppressing softening.

\section{Formulation of Constitutive Model}

Based on the monotonic test results of calcareous sand, it can be realized that the prepeak portion of stress-strain curve is hyperbolic shaped. The postpeak portion of dry calcareous sand and drained saturated calcareous sand is both threephased, while that of undrained saturated calcareous sand is 

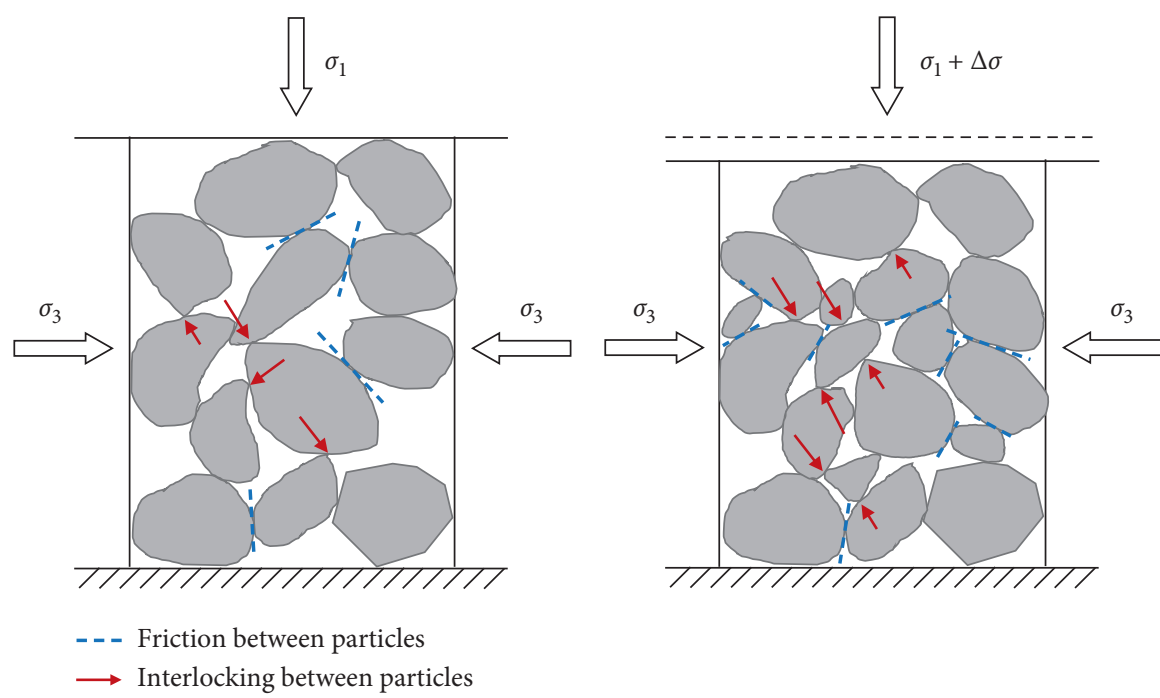

Figure 9: Sketch of deformation mechanism of calcareous sand.

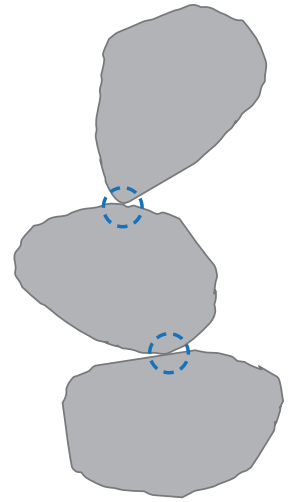

(a)

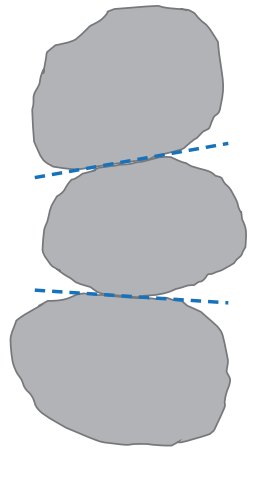

(b)

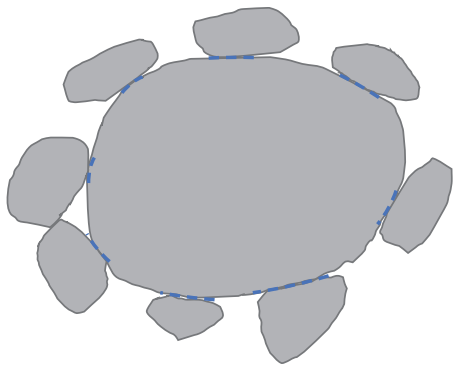

(c)

Figure 10: Typical contact patterns of calcareous sand particles. (a) Point-like contact. (b) Extended contact. (c) Contact L-S.

hyperbolic. Therefore, the model for calcareous sand should reflect the hyperbolic prepeak portion and the three-phase postpeak portion or the hyperbolic postpeak portion.

For the prepeak portion, the stress-strain relationship can be regarded as hyperbolic. Based on the hyperbolic elastic model of Ducan and Chang [23], the stress-strain relationship can be written as

$$
\sigma=\frac{\varepsilon_{1}}{a+b \varepsilon_{1}},
$$

where $\varepsilon_{1}$ is the axial strain, (\%), $\sigma$ is the principal stress difference, $\sigma=\sigma_{1}-\sigma_{3},(\mathrm{kPa})$, and $a$ and $b$ are the experimental parameters.

For the postpeak portion, the three-phase stress-strain curve is inverted S-shaped. It can be expressed with the following function:

$$
\sigma=\sigma_{p}-A\left[1-\frac{1}{1+\left(\left(\varepsilon_{1} / m\right)-\left(\varepsilon_{p} / m\right)\right)^{p}}\right],
$$

where $\varepsilon_{1}$ is the axial strain, (\%), $\sigma$ is the principal stress difference, $\sigma=\sigma_{1}-\sigma_{3},(\mathrm{kPa})$, and the parameters $\varepsilon_{p}$ and $\sigma_{p}$ correspond the abscissa and ordinate values of the starting point of equation (2), respectively. The parameter $A$ decides the ordinate value of terminal point of equation (2). Combined with the characteristic of postpeak stress-strain curve, it can be deduced that $\sigma_{p}$ is the peak stress $(\mathrm{kPa}), \varepsilon_{p}$ is the critical strain (\%), and $A$ is the difference between peak stress and residual stress $(\mathrm{kPa})$.

The value of the peak stress is related to the confining pressure and can be determined conveniently by Mohr-Coulomb failure criterion as

$$
\sigma_{P}=\frac{2 c \cdot \cos \varphi+2 \sigma_{3} \cdot \sin \varphi}{1-\sin \varphi},
$$

which has been described by Ducan and Chang [23], where $c$ is the cohesion and $\varphi$ is the angle of internal friction. Substituting the result into equation (1), the critical strain can be expressed by 


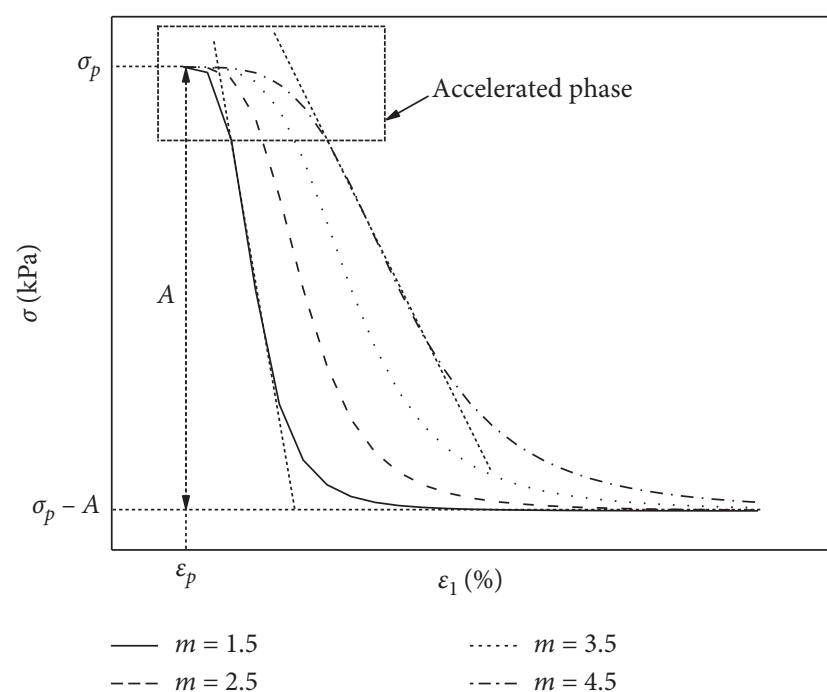

(a)

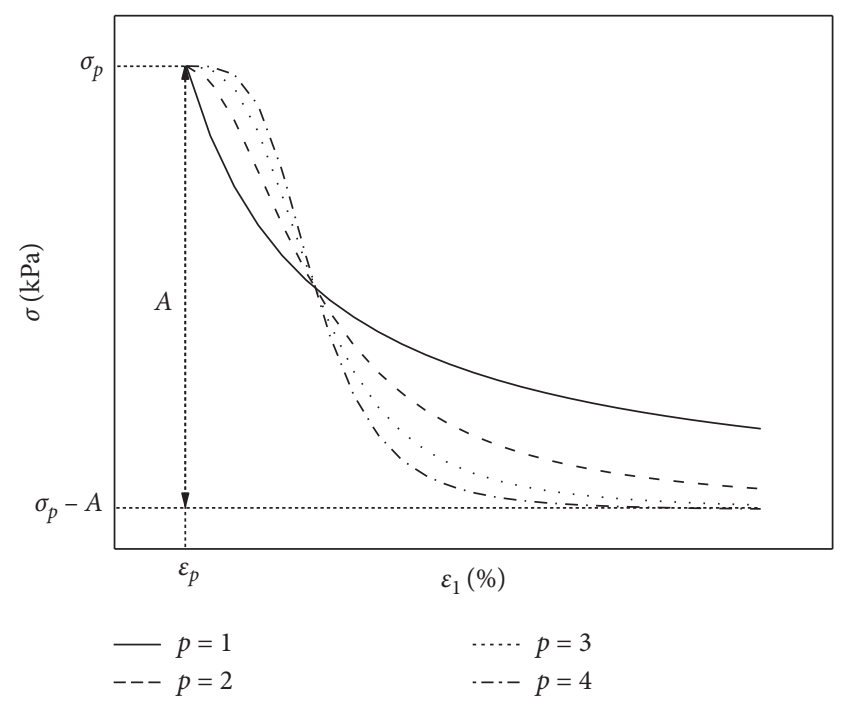

(b)

FIGURE 11: The influence of model parameters on the postpeak curve. Influence of (a) parameter $m$ and (b) parameter $p$.

$$
\varepsilon_{P}=\frac{2 a\left(c \cdot \cos \varphi+\sigma_{3} \cdot \sin \varphi\right)}{1-\sin \varphi-2 b\left(c \cdot \cos \varphi+\sigma_{3} \cdot \sin \varphi\right)} .
$$

In equation (2), the parameter $m$ is the softening rate factor. As shown in Figure 11(a), $m$ affects the softening rate of the accelerated phase and steady phase. The value of $m$ ranges effectively from 0 to positive infinity. The larger the $m$, the lower the softening rate on the accelerated phase and steady phase.

As shown in Figure 11(b), the parameter $p$ is a phase factor, which affects the amount of deformation required for the acceleration phase. The greater the $p$, the more the strain experienced during the acceleration phase. Especially, when the parameter $p$ is equal to 1 , there would be no acceleration phase. In this case, equation (2) reduces to

$$
\sigma=\left(\sigma_{p}-A\right)+A \frac{m}{m+\left(\varepsilon_{1}-\varepsilon_{p}\right)} .
$$

Meanwhile, the curve for the postpeak portion transforms from an inverted S-shaped curve to a hyperbolic one. This means that equation (2) not only fits for the dry calcareous sand and drained saturated calcareous sand but also fits for the undrained saturated calcareous sand by adjusting the value of parameter $p$. The $p$ value is valid when it is not less than 1 . The curve described by the model is more similar to the hyperbolic softening when $p$ is closer to 1 . As $p$ increases, the three-phase softening characteristic becomes more obvious.

Therefore, the mathematical model for the monotonic stress-strain relationship of calcareous sand can be expressed as

$$
\sigma= \begin{cases}\frac{\varepsilon_{1}}{a+b \varepsilon_{1}}, & \left(\sigma<\sigma_{p}\right), \\ \sigma_{p}-A\left[1-\frac{1}{1+\left(\left(\varepsilon_{1} / m\right)-\left(\varepsilon_{p} / m\right)\right)^{p}}\right], & \left(\sigma>\sigma_{p}\right) .\end{cases}
$$

Furthermore, in order to extend the above mathematical model to three dimensions, the generalized Hooke's law is introduced:

$$
\varepsilon_{1}=\frac{1}{E_{t}}\left[\sigma_{1}-v_{t}\left(\sigma_{2}+\sigma_{3}\right)\right]=\frac{1}{E_{t}}\left(\sigma_{1}-2 v_{t} \sigma_{3}\right),
$$

where $E_{t}$ and $v_{t}$ are the elastic modulus and Poisson's ratio, respectively. Equation (7) is substituted into equation (6), and a three-dimensional mathematical model can be obtained by combining the Duncan-Chang $E-\nu$ model:

$$
\sigma_{1}-\sigma_{3}= \begin{cases}\frac{1}{\left(E_{t} a /\left(\sigma_{1}-2 \nu_{t} \sigma_{3}\right)\right)+b}, & \left(\sigma<\sigma_{p}\right), \\ \sigma_{p}-A\left[1-\frac{1}{\left.\left.1+\left(\left(\sigma_{1}-2 \nu_{t} \sigma_{3}\right) / E_{t} m\right)-\left(\varepsilon_{p} / m\right)\right)^{p}\right],}\right. & \left(\sigma>\sigma_{p}\right),\end{cases}
$$

where $E_{t}$ and $v_{t}$ are represented as: 


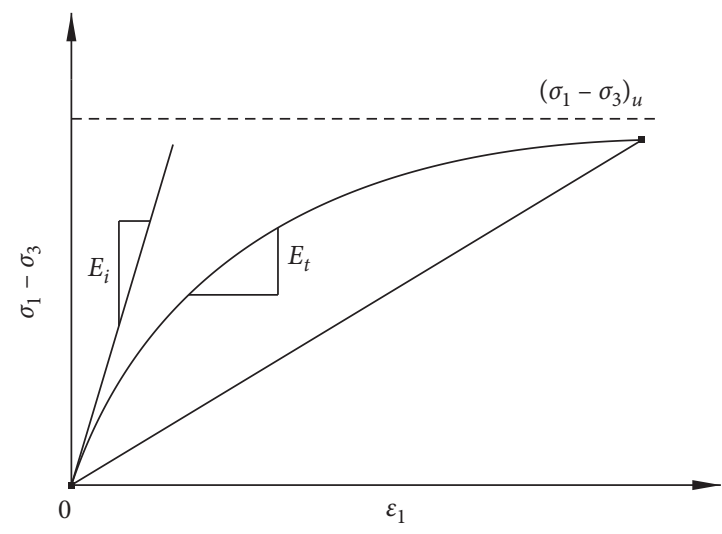

(a)

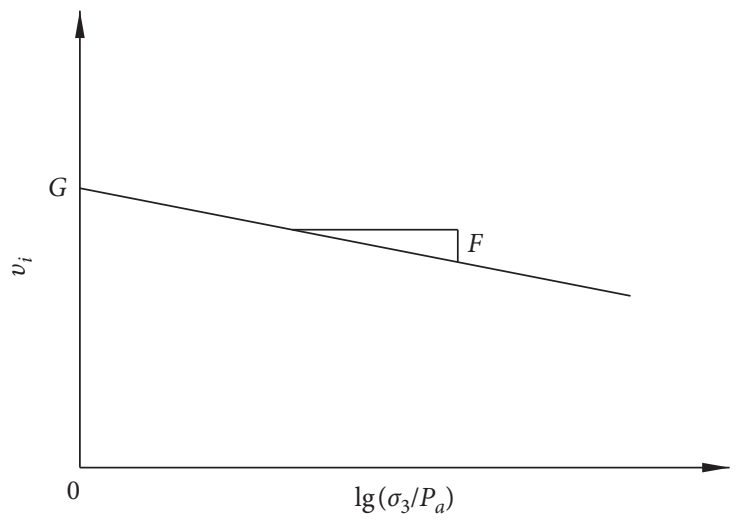

(c)

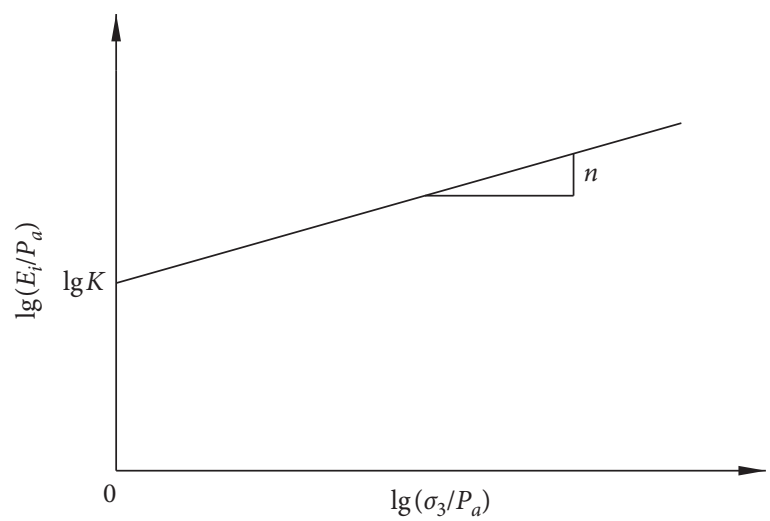

(b)

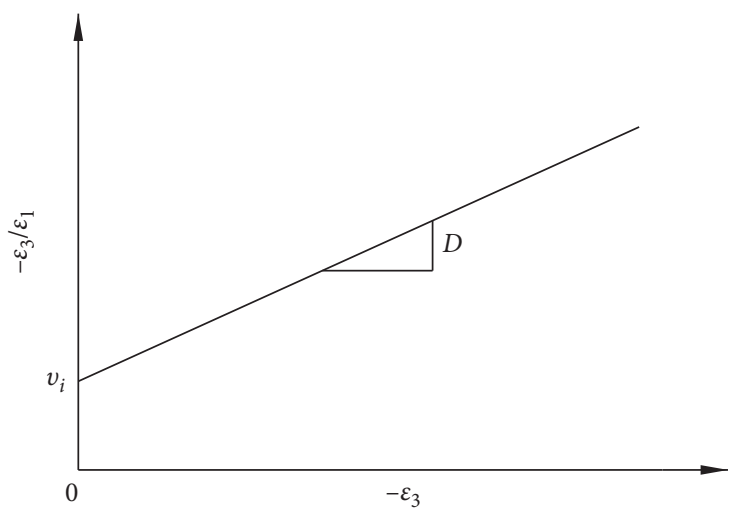

(d)

Figure 12: Determination of model parameters. Relation curve of (a) $\left(\sigma_{1}-\sigma_{3}\right)-\varepsilon_{1}$, (b) $\lg \left(E_{i} / P_{a}\right)-\lg \left(\sigma_{3} / P_{a}\right),(\mathrm{c}) v_{i}-\lg \left(\sigma_{3} / P_{a}\right)$, and $(\mathrm{d})\left(-\varepsilon_{3} /\right.$ $\left.\varepsilon_{1}\right)-\left(-\varepsilon_{3}\right)$.

$$
\left\{\begin{array}{l}
E_{t}=\left[1-R_{f} \frac{(1-\sin \varphi)\left(\sigma_{1}-\sigma_{3}\right)}{2 c \cos \varphi+2 \sigma_{3} \sin \varphi}\right]^{2} K P_{a}\left(\frac{\sigma_{3}}{P_{a}}\right)^{n}, \\
v_{t}=\frac{G-F \lg \left(\sigma_{3} / P_{a}\right)}{(1-X)^{2}}, \\
X=\frac{D\left(\sigma_{1}-\sigma_{3}\right)}{K P_{a}\left(\sigma_{3} / P_{a}\right)^{n}\left[1-\left(\left(R_{f}(1-\sin \varphi)\left(\sigma_{1}-\sigma_{3}\right)\right) /\left(2 c \cos \varphi+2 \sigma_{3} \sin \varphi\right)\right)\right]},
\end{array}\right.
$$

where $R_{f}$ is the failure ratio, which is the ratio between the deviatoric stress value at failure and the ultimate deviatoric stress value, and its calculation formula and schematic diagram are followed as equation (10) and Figure 12(a); $c$ is the cohesion; $\varphi$ is the angle of internal friction; $P_{a}$ is the atmospheric pressure; $K$ and $n$ are the experimental constants, respectively, representing the intercept and slope of the $\mathrm{lg}$ $\left(E_{i} / P_{a}\right)-\lg \left(\sigma_{3} / P_{a}\right)$ curve, in which $E_{i}$ is the initial elastic modulus (Figure 12(b)); $G$ and $F$ are material constants respectively, representing the intercept and slope of the $v_{i}-\lg \left(\sigma_{3} / P_{a}\right)$ curve, in which $v_{i}$ is the initial Poisson's ratio
(Figure 12(c)); and $D$ is the experimental constant, which is the reciprocal of the slope of the $\left(-\varepsilon_{3} / \varepsilon_{1}\right)-\left(-\varepsilon_{3}\right)$ curve (Figure 12(d)):

$$
R_{f}=\frac{\left(\sigma_{1}-\sigma_{3}\right)_{f}}{\left(\sigma_{1}-\sigma_{3}\right)_{u}} .
$$

\section{Model Validation}

To validate the feasibility of the mathematical model, the calculated and measured results are compared. fd1Equations 


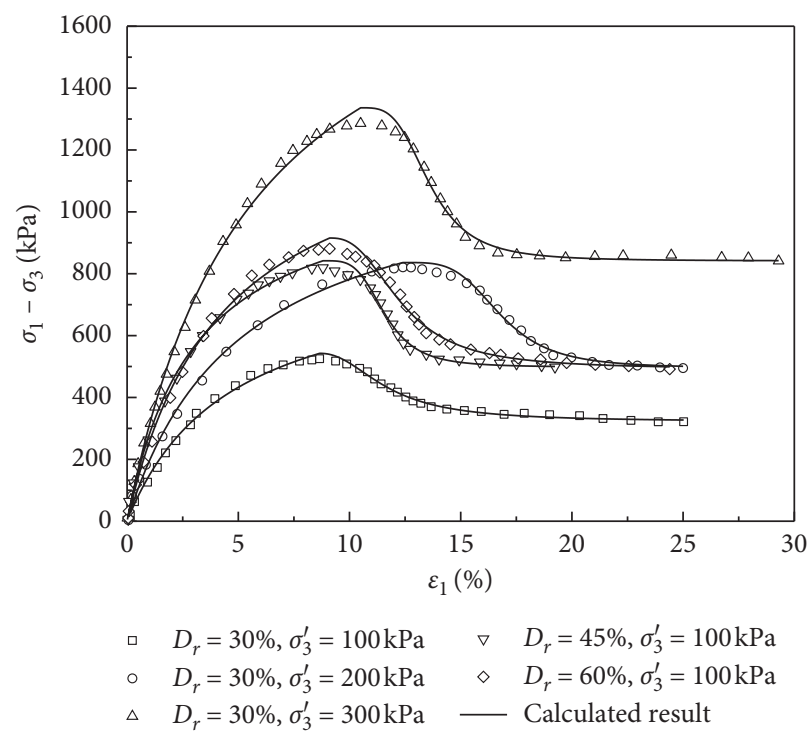

(a)

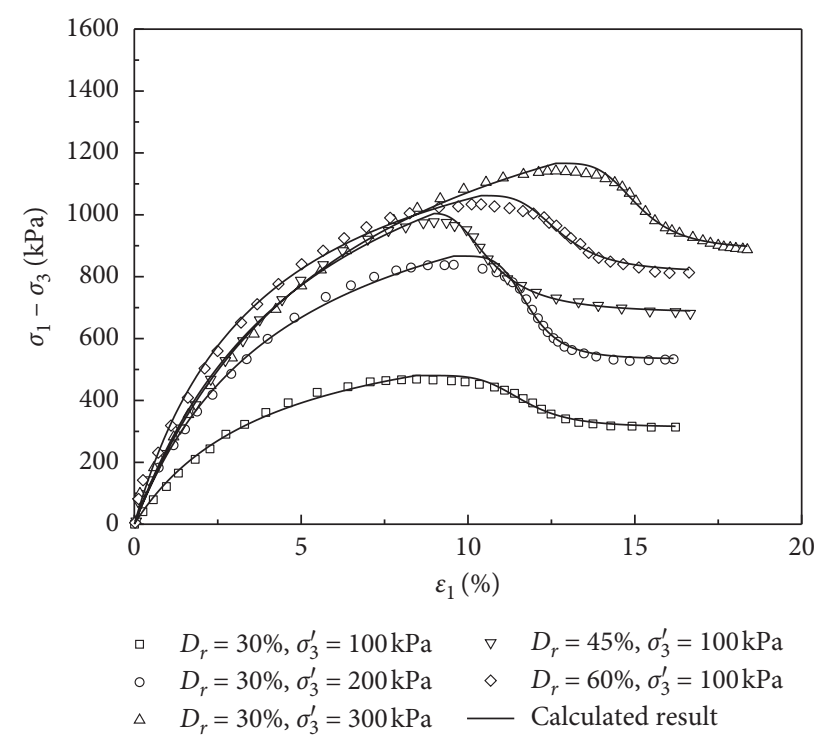

(b)

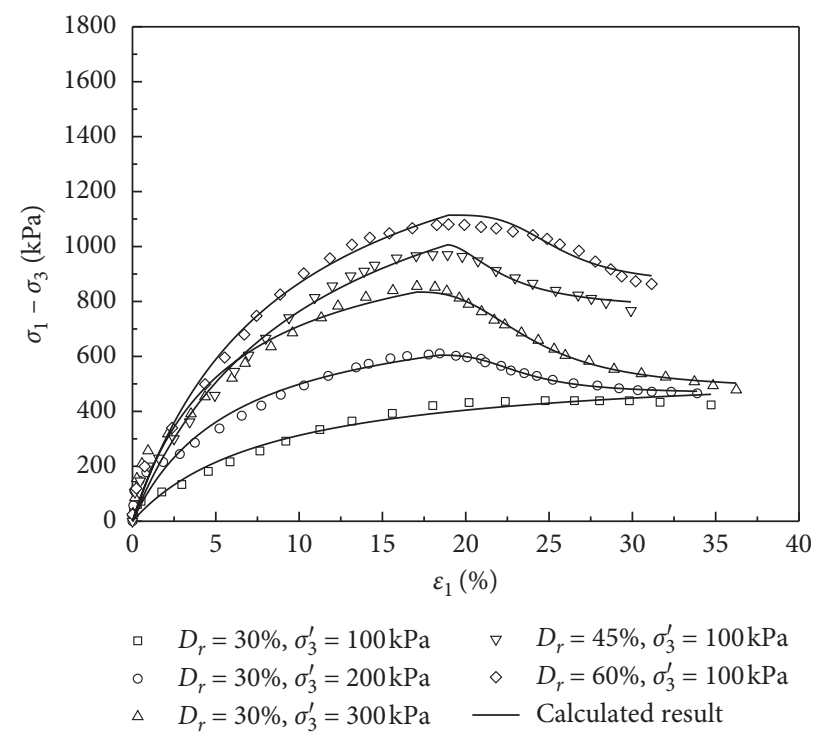

(c)

Figure 13: Comparison between test data and calculated results. (a) Dry calcareous sand. Saturated calcareous sand at (b) drained compression and (c) undrained compression.

(1) and (2)fd2 were used to fit with the prepeak portion and the postpeak portion of stress-strain curve, respectively. The value of parameters $a$ and $b$ in equation (1) were obtained through fitting with the test data of prepeak portion. To ensure the continuity of the piecewise function, the parameters $\varepsilon_{p}$ and $\sigma_{p}$ were approximated as the terminal points of the prepeak fitting result, and $A$ was determined to be the difference value between the substituted $\sigma_{p}$ and residual stress. Then, the value of parameters $m$ and $p$ in equation (2) were obtained through fitting with the test data of postpeak portion. The calculated results are shown in Figure 13. The values of the corresponding model parameters are shown in Table 4.

From Figure 13, it can be obviously seen that the model can well describe the monotonic stress-strain relationship of calcareous sand. Furthermore, the model parameters can be easily determined and their physical meanings are clear. Therefore, the mathematical model can be easily applied in the engineering practice.

In Section 2, the postpeak stress-strain curve of undrained saturated calcareous sand is regarded as hyperbolic. Whereas, the value of parameter $p$ is not equal to 1 , indicating that the fitting result with the hyperbolic function is not as good as that with the inverted S-shaped model. For the Toyoura sand, when the parameter $p$ is equal to 1 , the hyperbolic postpeak softening curve can be well described by the mathematical model. Compared with the unified model put forward by Jin et al. [44], the mathematical model has a better description, as shown in Figure 14. The unified model can be applied for both sand and clay, but the model has 
TABLE 4: Values of model parameters.

\begin{tabular}{|c|c|c|c|c|c|c|c|c|c|}
\hline Parameter & $D_{r}(\%)$ & $\sigma_{3}^{\prime}(\mathrm{kPa})$ & $a\left(10^{-3}\right)$ & $b\left(10^{-3}\right)$ & $\varepsilon_{p}(\%)$ & $\sigma_{p}(\mathrm{kPa})$ & $A(\mathrm{kPa})$ & $m$ & $p$ \\
\hline \multirow{5}{*}{ Dry calcareous sand } & 30 & 100 & 5.54 & 1.20 & 8.66 & 542.55 & 221.11 & 3.06 & 2.18 \\
\hline & 30 & 200 & 4.29 & 0.85 & 12.40 & 836.06 & 341.28 & 4.41 & 3.84 \\
\hline & 30 & 300 & 2.73 & 0.49 & 10.50 & 1336.31 & 495.01 & 3.12 & 3.44 \\
\hline & 45 & 200 & 2.67 & 0.88 & 8.81 & 841.81 & 343.71 & 2.78 & 3.83 \\
\hline & 60 & 200 & 3.16 & 0.75 & 9.11 & 915.34 & 423.81 & 3.25 & 2.59 \\
\hline \multirow{5}{*}{ Drained saturated calcareous sand } & 30 & 100 & 5.77 & 1.4 & 9.51 & 480.58 & 167.02 & 3.24 & 4.56 \\
\hline & 30 & 200 & 3.59 & 0.78 & 10.40 & 866.54 & 333.22 & 2.26 & 4.58 \\
\hline & 30 & 300 & 3.6 & 0.57 & 12.93 & 1166.31 & 278.99 & 2.49 & 3.81 \\
\hline & 45 & 200 & 3.38 & 0.62 & 8.98 & 1003.88 & 322.64 & 1.77 & 2.47 \\
\hline & 60 & 200 & 2.61 & 0.69 & 10.39 & 1061.89 & 248.52 & 2.42 & 3.39 \\
\hline \multirow{5}{*}{ Undrained saturated calcareous sand } & 30 & 100 & 14.54 & 1.75 & - & - & - & - & - \\
\hline & 30 & 200 & 7.68 & 1.24 & 18.44 & 604.49 & 138.79 & 5.24 & 2.66 \\
\hline & 30 & 300 & 5.04 & 0.90 & 17.07 & 834.28 & 356.21 & 7.03 & 2.59 \\
\hline & 45 & 200 & 6.7 & 0.64 & 18.91 & 1006.29 & 239.41 & 3.69 & 1.72 \\
\hline & 60 & 200 & 5.43 & 0.61 & 18.97 & 1114.28 & 250.82 & 6.70 & 3.32 \\
\hline
\end{tabular}

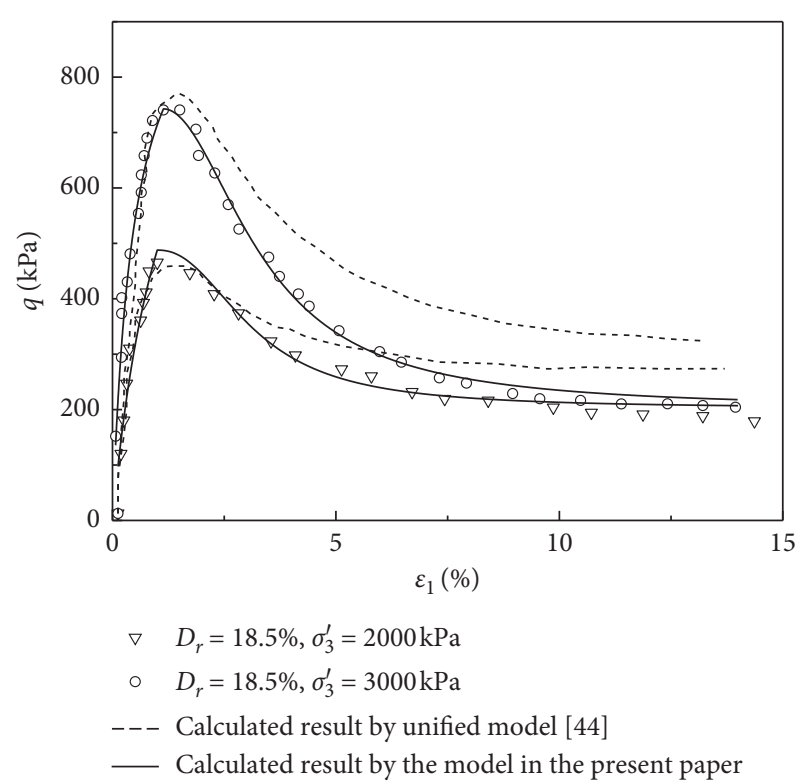

Figure 14: Comparison between test data and calculated result for undrained Toyoura sand.

thirteen parameters and their determination is also relatively complicated. In contrast, there are only seven parameters in the mathematical model in this paper. And, the parameters can be determined quickly based on the triaxial compression test result. Therefore, the mathematical model here is easier to be applied in engineering.

The prepeak stress-strain curves are almost all hyperbolic for various sands, so the hyperbolic function seems to be universal for sands. But, the postpeak softening of sand is different. For the sand with a characteristic of high compressibility, like calcareous sand, its postpeak softening presents an obvious three-phase shape. For the less compressible sand like Toyoura sand, the postpeak softening is hyperbolic, or even approximately linear. The obvious advantage of the mathematical model here is that it can well describe the stress-strain relationship, especially the postpeak multiphase softening characteristic. With the aid of this model, the effects of variables such as density and confining pressure as well as the mechanism of deformation and failure can be better understood.

\section{Conclusions}

According to the results of the triaxial compression test, the monotonic stress-strain curve of calcareous sand can be divided into two portions: prepeak portion and postpeak portion. For the dry sand and saturated calcareous sand under drainage condition, the postpeak softening portion can be further divided into three phases from the perspective of softening rate, i.e., accelerated phase, steady phase, and degradation phase. For the undrained saturated calcareous sand, the postpeak softening tendency appears as a two-phase hyperbolic shape. Moreover, it can be found that the residual stress is independent of the relative density for dry sand. The increase of confining pressure makes the strain softening more obvious and heightens the peak stress and residual stress; the starting and terminal points of strain softening under drainage compression are related to relative density and initial effective confining pressure. In addition, the amount of deformation required for the acceleration phase to total deformation is greater than that of dry sand; under undrained triaxial compression, increased initial confining pressure can enhance strainsoftening.

Based on the monotonic characteristic of calcareous sand, a mathematical model has been proposed, in which a hyperbolic function and an inverted S-shaped function were used to describe the prepeak portion and the postpeak portion, respectively. It is worth noting that the application of parameter $p$ enables the model to describe not only inverted S-shaped softening but also hyperbolic softening. The established model was validated with experiment results, showing that it can better describe the monotonic stress-strain relationship of calcareous sand. Besides, the physical meanings of the model parameters are clear and not hard to determine, making the model convenient to apply. 


\section{Data Availability}

All data used to support the findings of this study are available from the first author upon request.

\section{Disclosure}

Haotian Zhang and Zongmu Luo are regarded as co-first authors.

\section{Conflicts of Interest}

The authors declare that there are no conflicts of interest regarding the publication of this paper.

\section{Authors' Contributions}

Haotian Zhang and Zongmu Luo contributed equally to the work.

\section{Acknowledgments}

This work was financed and fully supported by the National Natural Science Foundation of China (Grant nos. 51774295 and 51808551), which is greatly appreciated by the authors.

\section{References}

[1] G. P. Chapman, "The sea-dredged sand and gravel industry of Great Britain," in Proceedings of a Symposium: Sea-Dredged Aggregates for Concrete, Slough, UK, December 1968.

[2] K. Yamazaki, "Viewpoints on using sea sand in concrete as fine aggregates in Japan," Cement and Concrete Research, vol. 12, pp. 72-76, 1974.

[3] J. Zheng and C. Bian, "A review of the present situation of the development and utilization of fine aggregate in Japan," EadyMixed Concrete, vol. 3, pp. 27-29, 2014, in Chinese.

[4] W. Gutt and R. J. Collins, "Sea-dredged aggregates in concrete," Building Research Establishment Information Paper, vol. 7, 1987.

[5] W. Liu, "Study on characteristics of dredged marine sand and the mechanical properties of concrete made with dredged marine sand," Bulletin of the Chinese Ceramic Society, vol. 33, pp. 15-22, 2014.

[6] S. Hasdemir, A. Tugrul, and M. Yilmaz, "The effect of natural sand composition on concrete strength," Construction \& Building Materials, vol. 112, pp. 940-948, 2016.

[7] A. Katz and H. Baum, "Effect of high levels of fines content on concrete properties," ACI Materials Journal, vol. 103, no. 6, p. 474, 2006.

[8] Md Safiuddin, S. N. Raman, and M. F. M. Zain, "Utilization of quarry waste fine aggregate in concrete mixtures," Journal of Applied Sciences Research, vol. 3, pp. 202-208, 2007.

[9] J. Xiao, C. Qiang, A. Nanni, and K. Zhang, "Use of sea-sand and seawater in concrete construction: current status and future opportunities," Construction and Building Materials, vol. 155, pp. 1101-1111, 2017.

[10] K. Newman, "Aspects of workability, strength, shrinkage and creep, sea dredged aggregates for concrete," in Proceedings of a Symposium, Sand and Gravel Association of Great Britain, Buckinghamshire, UK, December 1968.

[11] W. Deng and Y. Wang, "Investigating the factors affecting the properties of coral sand treated with microbially induced calcite precipitation," Advances in Civil Engineering, vol. 2018, Article ID 9590653, 6 pages, 2018.

[12] T. Feng, Y. Tang, Q. Wang, J. Zhang, and J. Song, "Experimental investigation of dynamic characteristics of subsea sand-silt mixtures," Advances in Civil Engineering, vol. 2019, Article ID 5619039, 9 pages, 2019.

[13] L. Ma, J. Wu, M. Wang, L. Dong, and H. Wei, "Dynamic compressive properties of dry and saturated coral rocks at high strain rates," Engineering Geology, vol. 272, p. 105615, 2020.

[14] Y. Xiao, L. Chen, and F. Qin, "Experimental study on the attenuation of stress wave in coral sand," Chinese Journal of Rock Mechanics and Engineering, vol. 37, pp. 1520-1529, 2018, in Chinese.

[15] X. Yu, L. Chen, Q. Fang, J. Zhang, D. Guo, and X. Hou, "Determination of attenuation effects of coral sand on the propagation of impact-induced stress wave," International Journal of Impact Engineering, vol. 125, pp. 63-82, 2019.

[16] Y. Xiao, L. Chen, and F. Qin, "A testing method on the attenuation of stress waves in loose porous media and its application to coral sand," Engineering Mechanics, vol. 36, no. 1, pp. 44-52, 2019, in Chinese.

[17] Y. Lv, X. Li, and Y. Wang, "Particle breakage of calcareous sand at high strain rates," Powder Technology, vol. 366, pp. 776-787, 2020.

[18] Y. Lv, J. Liu, and Z. Xiong, "One-dimensional dynamic compressive behavior of dry calcareous sand at high strain rates," Journal of Rock Mechanics and Geotechnical Engineering, vol. 11, no. 1, pp. 192-201, 2019.

[19] L. Wang, J. Mei, J. Wu, X. He, H. Li, and Q. Ding, "Mechanical properties and microscopic mechanism of coral sand-Cement mortar," Advances in Materials Science and Engineering, vol. 2020, Article ID 4854892, 11 pages, 2020.

[20] L. Ma, Z. Li, J. Liu, L. Duan, and J. Wu, "Mechanical properties of coral concrete subjected to uniaxial dynamic compression," Construction and Building Materials, vol. 199, pp. 244-255, 2019.

[21] M. Salem, H. Elmamlouk, and S. Agaiby, "Static and cyclic behavior of North Coast calcareous sand in Egypt," Soil Dynamics and Earthquake Engineering, vol. 55, pp. 83-91, 2013.

[22] Q. Fang, J. Zhang, L. Chen, J. Liu, J. Fan, and Y. Zhang, “An algorithm for the grain-level modelling of a dry sand particulate system," Modelling and Simulation in Materials Science and Engineering, vol. 22, Article ID 055021, 2014.

[23] J. M. Duncan and C.-Y. Chang, "Nonlinear analysis of stress and strain in soils," Journal of Soil Mechanics \& Foundations Division, vol. 96, 1970.

[24] L. Domaschuk and P. Valliappan, "Nonlinear settlement analysis by finite element," Computer-Aided Design, vol. 8, 1976.

[25] H. Izumi, K. Kamemura, and S. Sato, "Finite element analysis of stresses and movements in excavations," in Proceedings of the Numerical Methods in Geomechanics (Papers to 2nd International Conference, Blacksburg, VA, USA, June 1976.

[26] P. V. Lade and J. M. Duncan, "Elastoplastic stress-strain theory for cohesionless soil," Journal of Geotechnical and Geoenvironmental Engineering, vol. 101, no. 10, pp. 10371053, 1975.

[27] P. V. Lade, "Elasto-plastic stress-strain theory for cohesionless soil with curved yield surfaces," International Journal of Solids and Structures, vol. 13, no. 11, pp. 1019-1035, 1977.

[28] M. K. Kim and P. V. Lade, "Single hardening constitutive model for frictional materials: I. Plastic potential Function," 
International Journal of Rock Mechanics and Mining Sciences \& Geomechanics Abstracts, vol. 26, 1989.

[29] F. L. DiMaggio, "Material model for granular soils," Journal of Engineering Mechanics, vol. 97, 1971.

[30] L. Resende and J. B. Martin, "Formulation of drucker-prager cap model," Journal of Engineering Mechanics, vol. 111, no. 7, pp. 855-881, 1985.

[31] H. Matsuoka, "A stress-strain model for granular materials considering the mechanism of fabric change," Studies in Applied Mechanics, vol. 7, 1983.

[32] Dafalias and F. Yannis, "Bounding surface plasticity. I: mathematical foundation and hypoplasticity," Journal of Engineering Mechanics, vol. 112, no. 9, pp. 966-987, 1986.

[33] Z. L. Wang, Y. F. Dafalias, and C. K. Shen, "Bounding surface hypoplasticity model for sand," Journal of Engineering Mechanics, vol. 116, no. 5, pp. 983-1001, 1990.

[34] J. P. Bardet, "Hypoplastic model for sands," Journal of Engineering Mechanics, vol. 116, no. 9, pp. 1973-1994, 1990.

[35] W. Wu and E. Bauer, "A simple hypoplastic constitutive model for sand," International Journal for Numerical and Analytical Methods in Geomechanics, vol. 18, no. 12, pp. 833-862, 1994.

[36] M. G. Jefferies, "Nor-Sand: a simle critical state model for sand," Géotechnique, vol. 43, no. 1, pp. 91-103, 1993.

[37] W. Wu, E. Bauer, and D. Kolymbas, "Hypoplastic constitutive model with critical state for granular materials," Mechanics of Materials, vol. 23, no. 1, pp. 45-69, 1996.

[38] X. S. Li, "A sand model with state-dapendent dilatancy," Géotechnique, vol. 52, no. 3, pp. 173-186, 2002.

[39] M. T. Manzari and Y. F. Dafalias, "A critical state two-surface plasticity model for sands," Géotechnique, vol. 47, no. 2, pp. 255-272, 1997.

[40] H. S. Yu, "CASM: a unified state parameter model for clay and sand," International Journal for Numerical and Analytical Methods in Geomechanics, vol. 22, no. 8, pp. 621-653, 1998.

[41] L. Ma, Z. Li, M. Wang, H. Wei, and P. Fan, "Effects of size and loading rate on the mechanical properties of single coral particles," Powder Technology, vol. 342, pp. 961-971, 2019.

[42] ASTM Standard, "Test method for specific gravity of soil solids by gas pycnometer. ASTM standard D5550-14," Annual Book of ASTM Standards, 04.08, ASTM, West Conshohocken, PA, USA, 2014.

[43] ASTM Standard, "Test methods for maximum index density and unit weight of soils using a vibratory table," ASTM Standard D4253-16, ASTM, West Conshohocken, PA, USA, 2016.

[44] Y. Jin, Z. Yin, D. Zhang, and H. Huang, "Unified modeling of the monotonic and cyclic behaviors of sand and clay," Acta Mechanica Solida Sinica, vol. 28, no. 2, pp. 111-132, 2015.

[45] Y. Wang, "Investigation on the deformation mechanism of calcareous sand," Protective Engineering, vol. 40, pp. 35-39, 2018, in Chinese.

[46] J. Fonseca, P. Bésuelle, and G. Viggiani, "Micromechanisms of inelastic deformation in sandstones: an insight using X-ray micro-tomography," Géotechnique Letters, vol. 3, no. 2, pp. 78-83, 2013. 